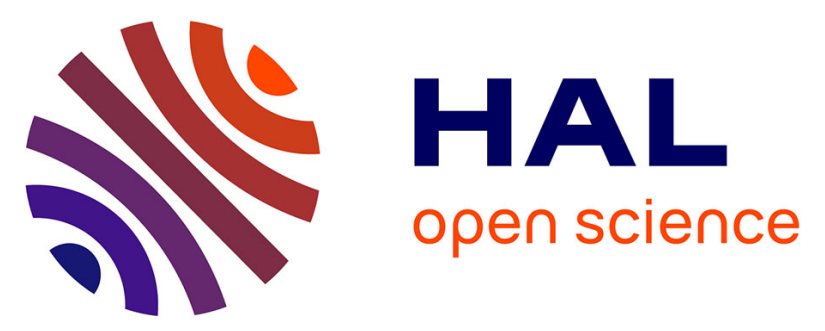

\title{
Capsular polysaccharide of Group B Streptococcus mediates biofilm formation in the presence of human plasma.
}

Fan Di Xia, Adeline Mallet, Elise Caliot, Cherry Gao, Patrick Trieu-Cuot, Shaynoor Dramsi

\section{To cite this version:}

Fan Di Xia, Adeline Mallet, Elise Caliot, Cherry Gao, Patrick Trieu-Cuot, et al.. Capsular polysaccharide of Group B Streptococcus mediates biofilm formation in the presence of human plasma.. Microbes and Infection, 2014, 17 (1), pp.71-6. 10.1016/j.micinf.2014.10.007 . pasteur-01108616

\section{HAL Id: pasteur-01108616}

https://hal-pasteur.archives-ouvertes.fr/pasteur-01108616

Submitted on 23 Jan 2015

HAL is a multi-disciplinary open access archive for the deposit and dissemination of scientific research documents, whether they are published or not. The documents may come from teaching and research institutions in France or abroad, or from public or private research centers.
L'archive ouverte pluridisciplinaire HAL, est destinée au dépôt et à la diffusion de documents scientifiques de niveau recherche, publiés ou non, émanant des établissements d'enseignement et de recherche français ou étrangers, des laboratoires publics ou privés. 

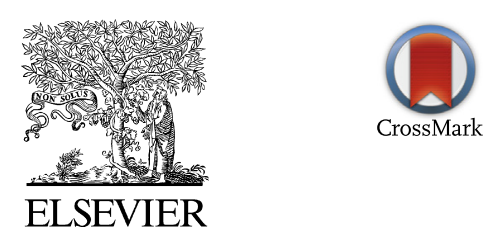

Institut Pasteur

Microbes and Infection 17 (2015) 71-76

www.elsevier.com/locate/micinf

Short communication

\title{
Capsular polysaccharide of Group B Streptococcus mediates biofilm formation in the presence of human plasma
}

\author{
Fan Di Xia ${ }^{\text {a,b,1 }}$, Adeline Mallet ${ }^{c}$, Elise Caliot ${ }^{\text {a,b }}$, Cherry Gao ${ }^{\text {a,b,2 }}$, Patrick Trieu-Cuot ${ }^{\text {a,b }}$, \\ Shaynoor Dramsi ${ }^{\mathrm{a}, \mathrm{b}, *}$ \\ ${ }^{a}$ Institut Pasteur, Unité des Bactéries Pathogènes à Gram positif, 75015 Paris, France \\ ${ }^{\mathrm{b}}$ Centre National de la Recherche Scientifique (CNRS ERL 3526), France \\ ${ }^{\mathrm{c}}$ Institut Pasteur, Imagopole, 75015 Paris, France
}

Received 16 May 2014; accepted 19 October 2014

Available online 27 October 2014

\begin{abstract}
Group B Streptococcus (GBS) is an asymptomatic colonizer of human mucosal surfaces that is responsible for sepsis and meningitis in neonates. Bacterial persistence and pathogenesis often involves biofilm formation. We previously showed that biofilm formation in medium supplemented with glucose is mediated by the PI-2a pilus. Here, biofilm formation was tested in cell culture medium supplemented with human plasma. GBS strains were able to form biofilms in these conditions unlike Group A Streptococcus (GAS) or Staphylococcus aureus. Analysis of mutants impaired for various surface components revealed that the GBS capsule is a key component in this process.

(c) 2014 Institut Pasteur. Published by Elsevier Masson SAS. All rights reserved.
\end{abstract}

Keywords: GBS; Streptococcus; Biofilm; Capsular polysaccharide; Human plasma

\section{Introduction}

Streptococcus agalactiae, also known as Group B Streptococcus (GBS), is the leading cause of neonatal infections in the developed world. Five (Ia, Ib, II, III, and V) out of the ten capsular serotypes characterized to date are responsible for the global burden of GBS [1]. Among these, strains of serotype III predominate in neonatal invasive infections whereas strains of serotype $\mathrm{V}$ are mainly responsible for adult invasive diseases. Several epidemiological studies pinpoint a single GBS serotype III clone, of sequence type 17 (or ST-17), as being responsible for the vast majority ( $>80 \%$ ) of meningitis cases

\footnotetext{
* Corresponding author. Institut Pasteur, Unite des Bacteries Pathogenes a Gram positif, 75015 Paris, France. Tel.: +331443894 87; fax: + 33145688938 . E-mail address: shaynoor.dramsi@pasteur.fr (S. Dramsi).

${ }^{1}$ Present address: Vanderbilt Box 210, 107 Avenue Louis Pasteur, Boston, MA 02115, USA.

2 Present address: Massachusetts Institute of Technology, Department of Biological Engineering, Cambridge, MA 02139, USA.
}

[2-5]. The ST-17 clone is now referred to as the hypervirulent GBS clonal complex 17 (CC-17) and $\mathrm{COH} 1$, a representative strain of this group, has been sequenced [6]. However, unlike other ST-17 strains, $\mathrm{COH} 1$ potently activates TLR2 in vitro [7]. We have therefore chosen BM110 as ST-17 representative strain. GBS serotypes are categorized based on immunologically distinct capsular polysaccharides owing to differences in oligosaccharide composition and linkage. Despite these differences, GBS capsular polysaccharides share common structural features. In particular, they all display a terminal sialic acid residue linked to $O-3$ of D-galactopyranosyl [8]. The synthesis of sialic acid and its modification by O-acetylation involves the four genes neuBCDA located at the $3^{\prime}$ end of the capsular polysaccharide operon [9,10]. Sialic acid is a major component of host glycoproteins and it is thought that capsular sialic acid allows GBS to evade host immune responses through molecular mimicry [11].

In addition to the capsule, GBS isolates elaborate surfaceanchored pili [12-14]. Pili have been proposed to contribute 
to colonization based on their ability to promote adhesion to host cells and biofilm formation $[15,16]$. Based on these properties, pili proteins have been investigated as candidate vaccine antigens [17]. Two genomic pilus islands (PI-1 and PI2) have been identified in GBS. The PI-2 locus exists in two variant forms: PI-2a is found in the vast majority of GBS strains of all serotypes (73\%) and PI-2b is restricted to ST-17 and a few other clinical isolates (27\%). GBS expressing specifically the PI-2a pilus were able to form biofilm in $\mathrm{LB}$ or $\mathrm{TH}$ media containing glucose $[15,16]$. In contrast, PI-1 and PI-2b did not contribute to biofilm formation [16]. In this brief report, we tested the ability of eight sequenced GBS strains to form biofilm in cell culture medium containing human plasma, a condition resembling that of the host environment, and unveiled a novel function of the capsular polysaccharide.

\section{Material and methods}

\subsection{Mutant construction}

The Cap-mutant was constructed as previously described by inactivating the $c p s E$ gene (formerly $c p s D$ ) with the promotor- and terminator-less kanamycin resistance gene aphA-3 [18]. The $\Delta n e u$ mutant was constructed as previously described [12] using splicing-by-overlap extension PCR carried out with the following primers $\left(5^{\prime}\right.$ to $\left.3^{\prime}\right)$ : Neu_Kpn, GAATAGGTACCATATGGCTTGGATTCCATGGTT; Neu_int1, TTGCGGCCGCAAAGCGCGCTTACCACAAGACACCGCAACATCTAC; Neu_int2, AAGCGCGCTTTGCGGCCGCAAGGATTGCATTTTACTCAAGAGGCT; and Neu_Bam, TTTATGGATCCTCGTCCTTAAGACCTAGAGCC. Mutants were confirmed by PCR and sequence analyses.

\subsection{Biofilm formation}

GBS and Streptococcus pyogenes (GAS) strains were grown in Todd-Hewitt (TH) broth whereas Staphylococcus aureus strain HG001 [19] was grown in Tryptic-Soy (TSB) broth. Human plasma was collected from healthy human volunteers by ICAReB platform. To avoid important variation from donor to donor, plasma was pooled from multiple donors. Overnight cultures were used to inoculate LB-glucose or RPMI-glucose or RPMI-glucose supplemented with human plasma at OD600 of 0.1 vortexed briefly and $180 \mu \mathrm{L}$ volumes were dispensed in 96 wells plate (Costar 3799; Corning, Inc., $\mathrm{NY}$ ) and incubated for $18 \mathrm{~h}$ at $37^{\circ} \mathrm{C}$. The OD600 of each culture was measured to ensure that all cells had reached stationary phase with a similar density, and the cells were washed twice in PBS and air-dried for $15 \mathrm{~min}$. Biofilms were stained with $0.4 \%$ crystal violet for $30 \mathrm{~min}$ and the wells were washed twice with PBS and air-dried. The bacterial biomass was then re-suspended for quantification in ethanol/acetone $(80 / 20)$ solution and OD540 was measured. When OD values were above 1, 2-fold dilutions were performed for accuracy. The assay was performed in triplicate and at least 4 independent experiments were performed.

\subsection{Scanning electron microscopy}

GBS strains were grown for $24 \mathrm{~h}$ at $37{ }^{\circ} \mathrm{C}$ in RPMI-G containing $15 \%$ human plasma on Thermanox slides. Samples were fixed with $2.5 \%$ glutaraldehyde in cacodylate buffer for $1 \mathrm{~h}$. Fixed bacteria were washed three times for $5 \mathrm{~min}$ in cacodylate buffer, postfixed for $1 \mathrm{~h}$ in $1 \%$ osmium, and rinsed with distilled water. Bacteria were dehydrated through a graded series of ethanol $(25,50,75,95$ and $100 \%)$ followed by critical point drying with $\mathrm{CO}_{2}$. Dried specimens were sputter coated twice with carbon with and observed with a JEOL JSM 6700F field emission scanning electron microscope.

\section{Results and discussion}

Biofilm formation was therefore tested in standard RPMI cell culture medium supplemented with $1 \%$ glucose (RPMIglucose) and 15\% human plasma; LB medium supplemented
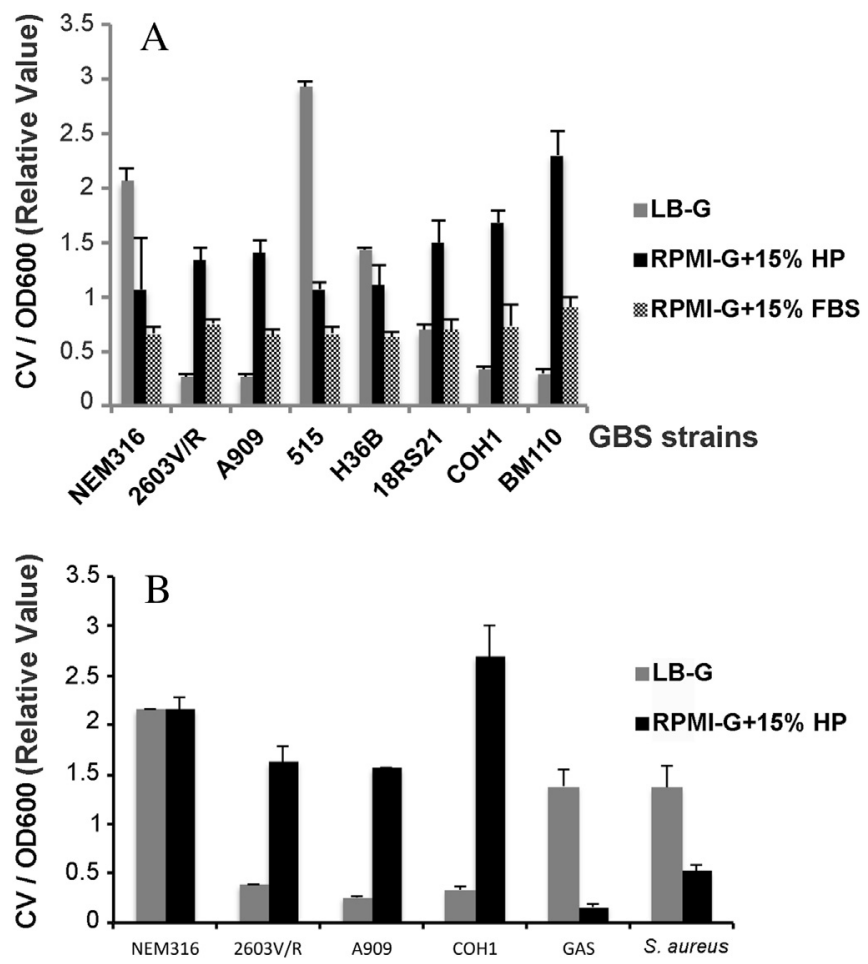

Fig. 1. Biofilm formation of eight GBS isolates in LB-glucose versus RPMIglucose supplemented with human plasma (A). GBS strains were grown at $37^{\circ} \mathrm{C}$ for $18 \mathrm{~h}$ in 96 wells polystyrene U-bottom plates in LB supplemented with $1 \%$ glucose or RPMI supplemented with $1 \%$ glucose and $15 \%$ human plasma (HP) or RPMI with $1 \%$ glucose and $15 \%$ fetal bovine serum (FBS). Overnight cultures grown in Todd-Hewitt medium were used to inoculate LBglucose or RPMI-glucose plasma media to obtain an initial OD600 of 0.1. After $18 \mathrm{~h}$ of culture at $37^{\circ} \mathrm{C}$, OD600 of each culture was measured to ensure that all cells had reached stationary phase at similar density, and cells were washed three times in PBS, air-dried and stained with crystal violet. Quantification was performed by solubilization of the stained biomass in ethanol/ acetone (80/20) and measuring the absorbance at $540 \mathrm{~nm}$. The assay was performed in triplicate and repeated at least three times independently. (B) Similar experiment comparing GBS (NEM316, 2603V/R, A909, COH1) to Group A Streptococus (M1 SF370) and S. aureus (HG001) strains. 
with $1 \%$ glucose (LB-glucose) was used as a control. In agreement with previous findings, biofilm formation in LBglucose was strictly dependent upon PI-2a expression [15] (Fig. 1). Specifically, of the strains tested, only the three expressing the PI-2a pilus - namely strains NEM316, 515 and H36B - were able to form biofilm in LB-glucose (Fig. 1A). However, all eight GBS strains tested, including the ST-17 strains $\mathrm{COH} 1$ and $\mathrm{BM} 110$, were able to form similar amounts of biofilm in RPMI-glucose containing $15 \%$ human plasma irrespective of their serotypes, STs, or pili type (Fig. 1). In RPMI-glucose supplemented with 15\% FBS, all GBS strains formed a low amount of biofilm (Fig. 1A). Unlike GBS strains, Group A Streptococcus (M1 strain SF370) and $S$. aureus (HG001) were unable to form biofilms in RPMIglucose supplemented with human plasma (Fig. 1B).

Due to the clinical significance of the ST-17 strains, BM110 was selected to characterize the component(s) involved in biofilm formation in the presence of human plasma. We first showed that BM110 formed more dense biofilm in RPMIglucose medium supplemented with human plasma compared to RPMI-glucose medium alone, or RPMI-glucose supplemented with bovine serum (Fig. 2A). Growth curve measurements indicated that BM110 reached a higher density in RPMI-glucose supplemented with human plasma (Fig. 2B). Human plasma is rich in proteins (albumin 50\%; globulins $20 \%$; fibrinogen $5 \%$ ) and fatty acids (mostly C18 unsaturated fatty acid). It was previously shown that exogenous fatty acids present in the human plasma could be incorporated by GBS and potentially changed bacterial membrane composition and fluidity [20]. We therefore asked whether mimicking the lipid composition of human plasma would contribute to biofilm formation. Tween 80 is a polysorbitol ester containing approximately $70 \%$ oleic acid, a mono-unsaturated C18 lipid. Adding Tween 80 at $0.1 \% \mathrm{v} / \mathrm{v}$ to RPMI-glucose to mimic the lipid composition of human plasma increased BM110 biofilm formation (Fig. 2C). However, total biofilm production was significantly lower to that obtained when bacteria were incubated in RPMI-glucose supplemented with $15 \%$ human plasma. These results suggest that the protein content of human plasma may also contribute to biofilm formation. Similarly to the findings reported by d'Urzo et al. [21], pretreatment of human plasma with proteinase $\mathrm{K}$ $\left(0.1-100 \mu \mathrm{g} \mathrm{ml}^{-1}\right)$ led to a significant reduction of biofilm formation, which was apparent at an enzyme concentration of $0.1 \mu \mathrm{g} \mathrm{ml}^{-1}$ and maximal at $1 \mu \mathrm{g} \mathrm{ml}^{-1}$ (Fig. 2D). We next investigated the components contributing to biofilm stability in human plasma. BM110 pre-formed biofilms were treated for $30 \mathrm{~min}$ at $37{ }^{\circ} \mathrm{C}$ with DNAse I $\left(20 \mu \mathrm{g} \mathrm{ml}{ }^{-1}\right)$, RNAseA $\left(200 \mu \mathrm{g} \mathrm{ml}^{-1}\right)$, sodium meta-periodate $(10 \mathrm{mM})$ to oxidize carbohydrates, or proteinase $\mathrm{K}\left(100 \mu \mathrm{g} \mathrm{ml}^{-1}\right)$ before staining with crystal violet. As shown in Fig. S1, only treatment with proteinase $\mathrm{K}$ led to a significant reduction in the density of the biofilm, indicating that proteins play a major role in the cohesion process.

To identify the bacterial structures involved in biofilm formation, we compared the ability of BM110 to form biofilm with that of isogenic mutants impaired for the synthesis of major surface components. ST-17 strains were previously shown to bind human fibrinogen at a higher level compared to other GBS isolates through the specific Srr2 (serine-rich repeat) cell wall-anchored glycoprotein [22]. Because fibrinogen is a major component of human plasma, we first tested
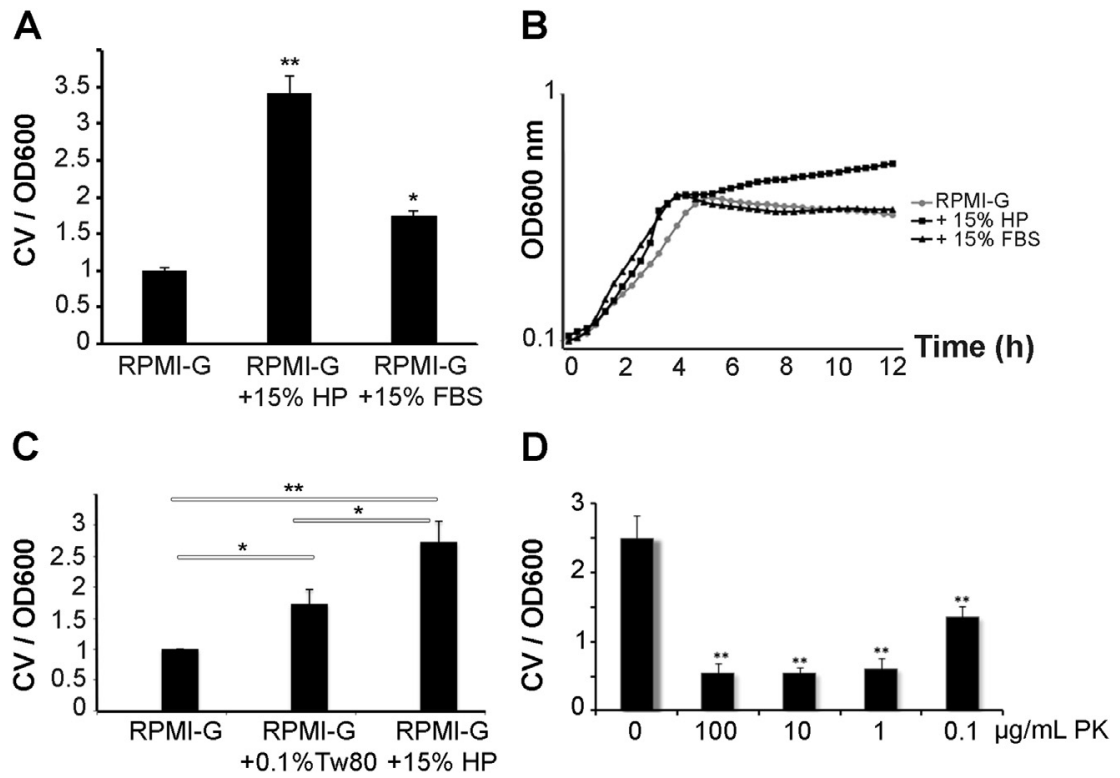

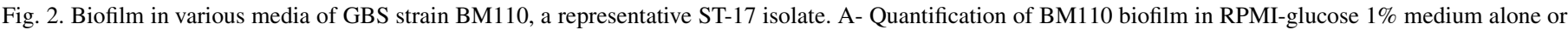

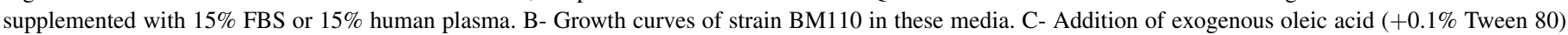

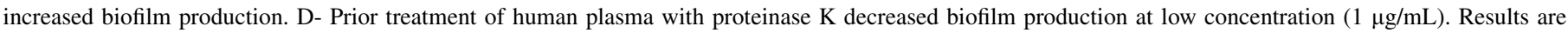

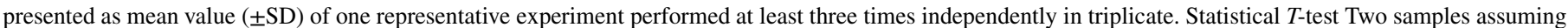
equal variances was applied: $* p<0.01$ and $* * p<0.001$. 
the capacity of a BM110 $\Delta s r r 2$ mutant to form a biofilm in human plasma. However, this mutant had no defect for biofilm formation (data not shown). Human serum was previously shown to increase expression of cell wall-anchored proteins such as C5a peptidase and alpha $\mathrm{C}$ protein antigen [23,24]. However, we show here that BM110:srtA* mutant, that is unable to covalently anchor LPXTG-containing proteins to peptidoglycan, is comparable to the wild-type strain, indicating that cell wall-anchored proteins are not required for biofilm formation in RPMI-glucose medium containing human plasma (Fig. 3A).
Unlike the srtA mutant, the non-capsulated $\Delta$ cpsE mutant (hereafter referred as Cap-) was significantly impaired in its ability to form biofilm in human plasma (Fig. 3A). Since cpsE is the fifth gene in a large capsule biosynthetic operon consisting of sixteen genes, complementation of the noncapsulated mutant was not examined. All GBS sequenced isolates belonging to various serotypes (serotype Ia: A909 and 515; Ib: H36B; II: 18RS21; III: NEM316, COH1, and BM110; and V: $2603 \mathrm{~V} / \mathrm{R})$ were able to form biofilm in the presence of human plasma (Fig. 1). We therefore wondered if the terminal sialic acid common to all GBS capsular polysaccharides could

\section{A}

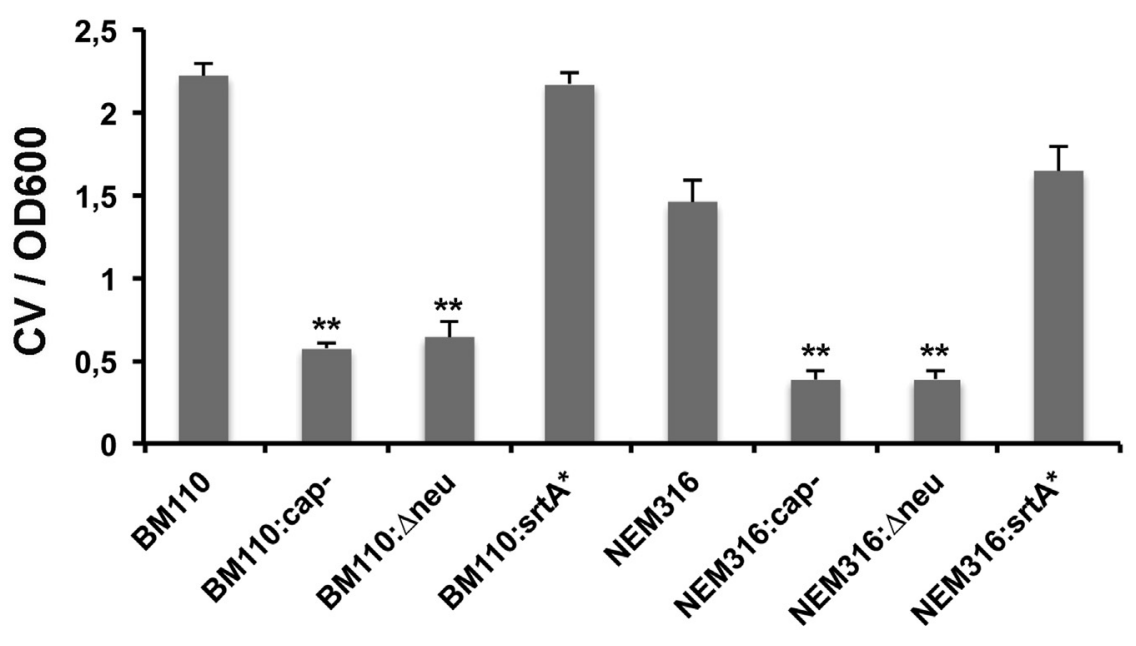

B

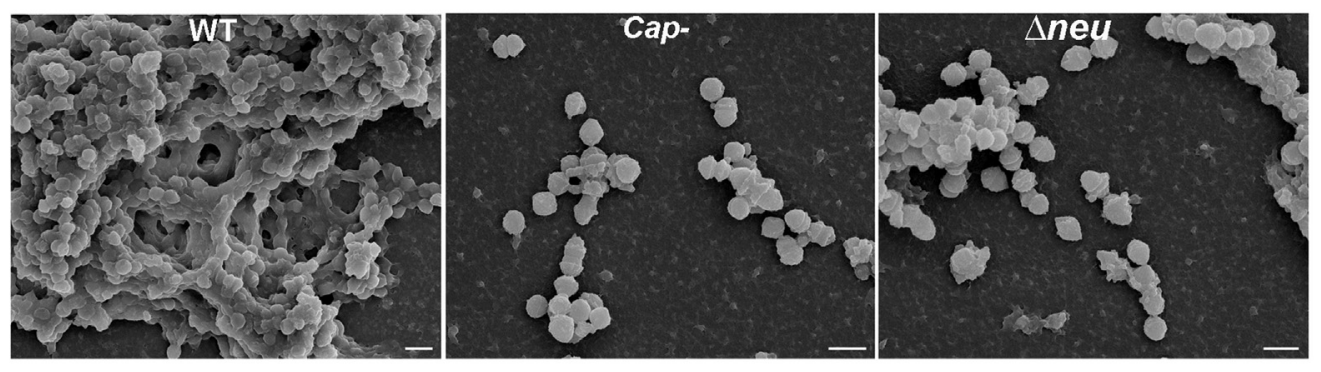

C
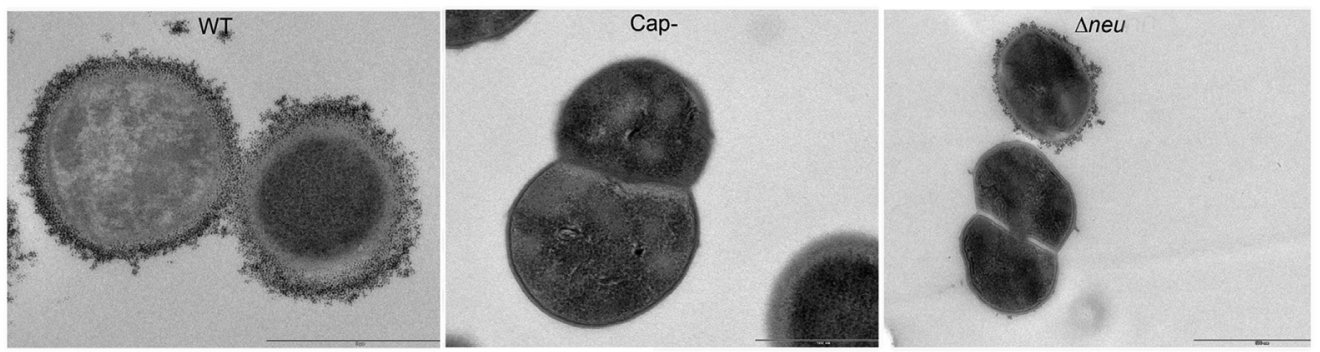

Fig. 3. Role of GBS capsular polysaccharide for biofilm formation in human plasma. A- Deletion of cpsE (cap-), neuBCDA ( $\triangle n e u$ ) and srtA catalytic codons $\left(s r t A^{*}\right)$ were introduced both in BM110 and NEM316 genetic backgrounds. A- Biofilm formation in RPMI-glucose supplemented with $15 \%$ human plasma of GBS mutants impaired for capsule formation (cap- or $\Delta$ neu) or unable to anchor LPXTG proteins on the cell-wall (SrtA*). B- Visualization of the BM110 biofilm architecture by scanning electron microscopy as compared to the non-biofilm producers $c a p$ - or $\Delta$ neu. C-Capsular polysaccharide labeling using ferritin detected by transmission electron microscopy in BM110 (WT), Cap- or $\Delta$ neu mutants. 
be a key determinant in this biofilm formation process in human plasma. To test this hypothesis, we constructed a BM110 mutant derivative deleted for the neuBCDA genes. Interestingly, the BM110:Aneu mutant was significantly reduced in its biofilm formation capacity in RPMI-glucose medium containing $15 \%$ human plasma. This reduction was comparable to that observed for the non-capsulated Capvariant (Fig. 3A). Similar results were obtained for the ST-23 serotype III NEM316 lacking the cpsE or neuBCDA genes (Fig. 3A). As shown in ST-17 strain BM110, inactivation of SrtA in strain NEM316 did not result in impaired biofilm formation in the presence of human plasma (Fig. 3A). Deletion of cpsE in the ST-110 serotype V 2603V/R strain also impaired biofilm formation (data not shown). As shown in Fig. S2, both capsule deficient mutants formed better biofilms than WT strain in RPMI-glucose alone. Addition of increasing amounts of human plasma (1\%,5\% and 20\%) led to a switch for biofilm formation between WT and mutant strains.

Crystal violet staining on microtiter plate is a standard assay to quantify biofilm but it does not allow to get access to the three-dimensional structure of biofilm. To better visualize BM110-induced biofilm architecture in human plasma, we performed scanning electron microscopy using Thermanox ${ }^{\circledR}$ coverslips. As shown in Fig. $3 \mathrm{~B}$, as opposed to the $\Delta c p s E$ or $\Delta n e u$ variants, BM110 formed highly cohesive biofilms with bacterial cells enmeshed into matrix. Sialylation of GBS capsular polysaccharide was previously reported to be required for optimal capsule polymerization and biosynthesis [25]. Therefore, the biofilm reduction observed with the $\Delta n e u$ mutants could be due to a defect in capsule biosynthesis. To test this possibility, bacterial surface components were visualized using ferritin labeling by transmission electron microscopy of the BM110 wild-type strain and isogenic $\Delta$ cpsE and $\Delta$ neu mutants (Fig. 3C). About $80 \%$ of the BM110 cells were labeled with ferritin whereas no staining was detected for the

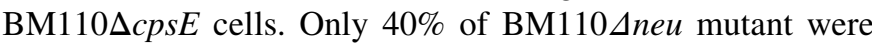
stained with ferritin confirming the previously reported reduction in capsule synthesis for asialo mutants [25].

Interestingly, a very recent work demonstrated that strains of the ST-17 hypervirulent complex form robust biofilms under acidic conditions in Todd Hewitt broth [21]. We report here that GBS clinical isolates irrespective of their serotypes can form biofilm in RPMI cell medium supplemented with human plasma. We show that both lipids and proteins present in human plasma contribute to this process. Importantly, we found that GBS capsular polysaccharide is required for biofilm formation in the presence of human plasma. Sialylated capsular polysaccharides are crucial virulence factors of extracellular pathogens that cause meningitis (GBS, pneumococcus, Escherichia coli, and Neisseria meningitidis) and prevent complement-mediated phagocytosis by immune cells. This study reports, for the first time, a major role for capsular polysaccharide in biofilm formation. Future studies will investigate biofilm formation in human tissues and the contribution of biofilm for GBS persistence and pathogenesis, particularly in the context of emerging prosthetic jointassociated infections in adults.

\section{Conflict of interest}

There is no conflict of interest.

\section{Acknowledgments}

We thank Pr Gunnar Lindahl for the kind gift of strains BM110 wild-type and its isogenic non-capsulated BM110 Capmutant. We also thank the personnel of the ICAReB Plateform for excellent assistance. This study has received funding from the French National Research Agency (ANR Blanc Fatty-Bact grant $\mathrm{n}^{\circ}$ ANR-10-BLAN-1321 and ANR Blanc Glyco-Path grant number $n^{\circ}$ ANR-10-BLANC-1314) and from the French Government's Investissement d'Avenir program, Laboratoire d'Excellence "Integrative Biology of Emerging Infectious Diseases" (grant $\mathrm{n}^{\circ}$ ANR-10-LABX-62-IBEID). We herein declare that all authors have seen and approved the content of this manuscript and do not have any conflict of interest.

\section{Appendix A. Supplementary data}

Supplementary data related to this article can be found at http://dx.doi.org/10.1016/j.micinf.2014.10.007.

\section{References}

[1] Phares CR, Lynfield R, Farley MM, Mohle-Boetani J, Harrison LH, Petit S, et al. Epidemiology of invasive group B streptococcal disease in the United States, 1999-2005. J Am Med Assoc 2008;299:2056-65.

[2] Bohnsack JF, Whiting A, Gottschalk M, Dunn DM, Weiss R, Azimi PH, et al. Population structure of invasive and colonizing strains of Streptococcus agalactiae from neonates of six U.S. academic centers from 1995 to 1999. J Clin Microbiol 2008;46:1285-91.

[3] Jones N, Oliver KA, Barry J, Harding RM, Bisharat N, Spratt BG, et al. Enhanced invasiveness of bovine-derived neonatal sequence type 17 group B streptococcus is independent of capsular serotype. Clin Infect Dis 2006; $42: 915-24$.

[4] Musser JM, Mattingly SJ, Quentin R, Goudeau A, Selander RK. Identification of a high-virulence clone of type III Streptococcus agalactiae (group B Streptococcus) causing invasive neonatal disease. Proc Natl Acad Sci U. S. A 1989;86:4731-5.

[5] Tazi A, Disson O, Bellais S, Bouaboud A, Dmytruk N, Dramsi S, et al. The surface protein HvgA mediates group B streptococcus hypervirulence and meningeal tropism in neonates. J Exp Med 2010;207:2313-22.

[6] Tettelin H, Masignani V, Cieslewicz MJ, Donati C, Medini D, Ward NL, et al. Genome analysis of multiple pathogenic isolates of Streptococcus agalactiae: implications for the microbial "pan-genome". Proc Natl Acad Sci U S A 2005;102:13950-5.

[7] Henneke P, Dramsi S, Mancuso G, Chraibi K, Pellegrini E, Theilacker C, et al. Lipoproteins are critical TLR2 activating toxins in group B streptococcal sepsis. J Immunol 2008;180:6149-58.

[8] Cieslewicz MJ, Chaffin D, Glusman G, Kasper D, Madan A, Rodrigues S, et al. Structural and genetic diversity of group B streptococcus capsular polysaccharides. Infect Immun 2005; 73:3096-103.

[9] Lewis AL, Nizet V, Varki A. Discovery and characterization of sialic acid O-acetylation in group B streptococcus. Proc Natl Acad Sci U S A 2004:101:11123-8.

[10] Wessels MR, Haft RF, Heggen LM, Rubens CE. Identification of a genetic locus essential for capsule sialylation in type III group B streptococci. Infect Immun 1992;60:392-400. 
[11] Chang YC, Olson J, Beasley FC, Tung C, Zhang J, Crocker PR, et al. Group B streptococcus engages an inhibitory siglec through sialic acid mimicry to blunt innate immune and inflammatory responses in vivo. PLoS Pathog 2014;10:e1003846.

[12] Dramsi S, Caliot E, Bonne I, Guadagnini S, Prevost MC, Kojadinovic M, et al. Assembly and role of pili in group B streptococci. Mol Microbiol 2006;60:1401-13.

[13] Lauer P, Rinaudo CD, Soriani M, Margarit I, Maione D, Rosini R, et al. Genome analysis reveals pili in group B streptococcus. Science 2005;309:105.

[14] Rosini R, Rinaudo CD, Soriani M, Lauer P, Mora M, Maione D, et al. Identification of novel genomic islands coding for antigenic pilus-like structures in Streptococcus agalactiae. Mol Microbiol 2006;61:126-41.

[15] Konto-Ghiorghi Y, Mairey E, Mallet A, Dumenil G, Caliot E, TrieuCuot $\mathrm{P}$, et al. Dual role for pilus in adherence to epithelial cells and biofilm formation in Streptococcus agalactiae. PLoS Pathog 2009;5:e1000422.

[16] Rinaudo CD, Rosini R, Galeotti CL, Berti F, Necchi F, Reguzzi V, et al. Specific involvement of pilus type $2 \mathrm{a}$ in biofilm formation in group $\mathrm{B}$ streptococcus. PLoS One 2010;5:e9216.

[17] Buccato S, Maione D, Rinaudo CD, Volpini G, Taddei AR, Rosini R, et al. Use of Lactococcus lactis expressing pili from group B streptococcus as a broad-coverage vaccine against streptococcal disease. J Infect Dis 2006; 194:331-40.

[18] Poyart C, Pellegrini E, Gaillot O, Boumaila C, Baptista M, Trieu-Cuot P. Contribution of Mn-cofactored superoxide dismutase (SodA) to the virulence of Streptococcus agalactiae. Infect Immun 2001;69:5098-106.
[19] Herbert S, Ziebandt AK, Ohlsen K, Schafer T, Hecker M, Albrecht D, et al. Repair of global regulators in Staphylococcus aureus 8325 and comparative analysis with other clinical isolates. Infect Immun 2010;78:2877-89.

[20] Brinster S, Lamberet G, Staels B, Trieu-Cuot P, Gruss A, Poyart C. Type II fatty acid synthesis is not a suitable antibiotic target for gram-positive pathogens. Nature 2009;458:83-6.

[21] D'Urzo N, Martinelli M, Pezzicoli A, De Cesare V, Pinto V, Margarit I, et al. Acidic pH strongly enhances in vitro biofilm formation by a subset of hypervirulent ST-17 Streptococcus agalactiae strains. Appl Environ Microbiol 2014;80:2176-85.

[22] Seo HS, Minasov G, Seepersaud R, Doran KS, Dubrovska I, Shuvalova L, et al. Characterization of fibrinogen binding by glycoproteins Srr1 and Srr2 of Streptococcus agalactiae. J Biol Chem 2013;288:35982-96.

[23] Gleich-Theurer U, Aymanns S, Haas G, Mauerer S, Vogt J, Spellerberg B. Human serum induces streptococcal C5a peptidase expression. Infect Immun 2009;77:3817-25.

[24] Yang Q, Zhang M, Harrington DJ, Black GW, Sutcliffe IC. A proteomic investigation of Streptococcus agalactiae reveals that human serum induces the $\mathrm{C}$ protein beta antigen and arginine deiminase. Microbes Infect 2011;13:757-60.

[25] Chaffin DO, Mentele LM, Rubens CE. Sialylation of group B streptococcal capsular polysaccharide is mediated by cpsK and is required for optimal capsule polymerization and expression. J Bacteriol 2005; 187:4615-26. 